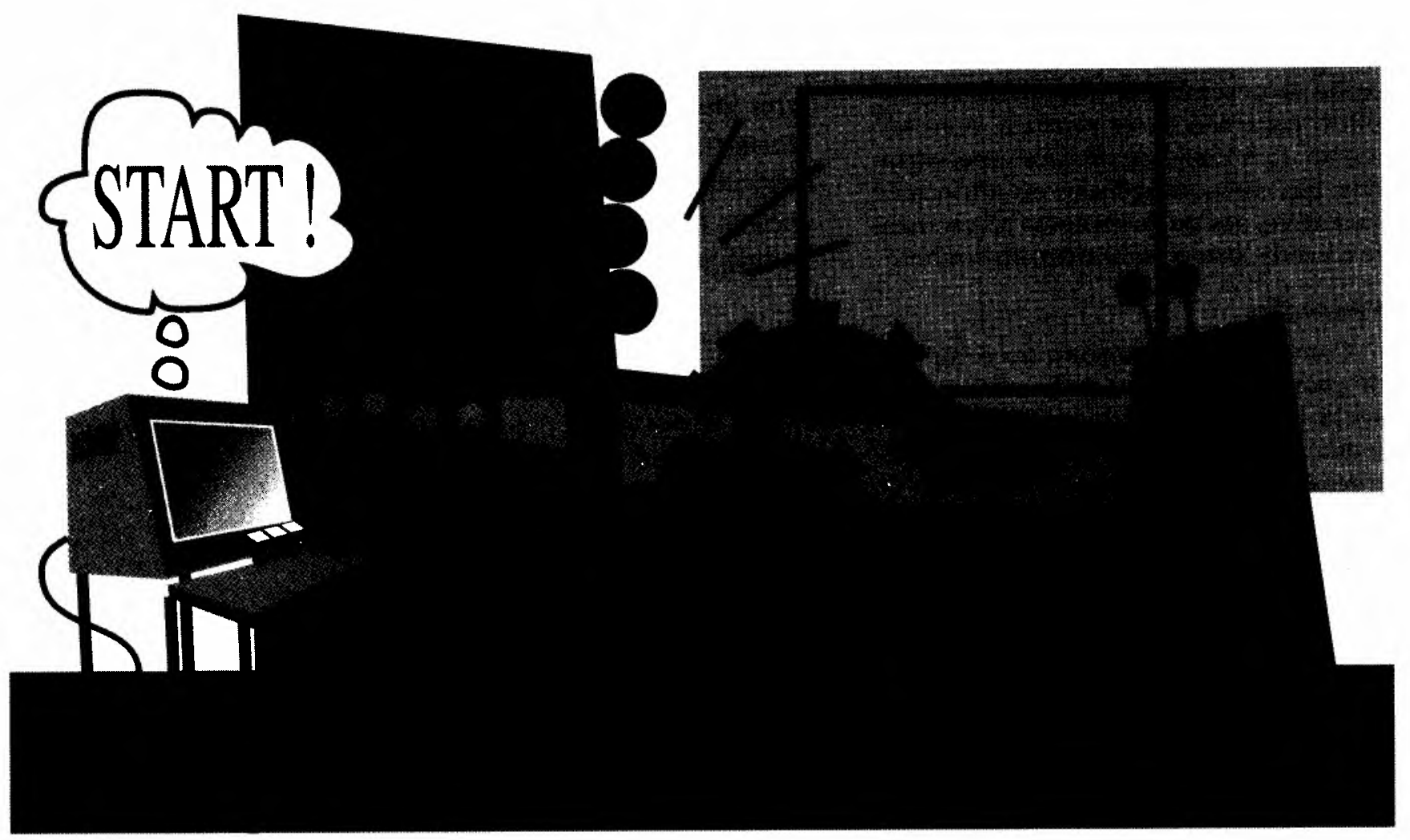

\title{
DIFUSÃO DA TECNOLOGIA DE BASE MICROELETRÔNICA NA INDÚSTRIA DE PROCESSO CONTÍNUO
}

Francisco Lima C. Teixeira

Professor Adjunto do Mestrado em Administração e Pesquisador do Núcleo Política e Gestão de Ciência e Tecnologia (NACIT) da Universidade Federal da Bahia.

* RESUMO: O objetivo deste trabalho é apresentar e discutir dados e informações a respeito do processo de difusão da tecnologia digital na indústria de processo contínuo no Brasil. Os dados apresentados indicam o alto grau de difusão dessa tecnologia em relação à indústria de processo intermitente. A base instalada no Brasil é, proporcionalmente, maior do que a dos países industrializados. A decisão de

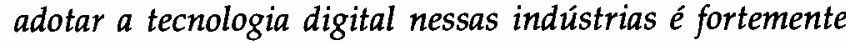
influenciada por variáveis de natureza "sócio-institucional", uma vez que as informações técnicas e econômicas nem sempre estão disponíveis no momento da decisão. Entre as variáveis "sócio-institucionais", analisa-se a influência da política de reserva de mercado no processo de difusão.
* PALAVRAS-CHAVE: Microeletrônica, difusão, processocontínuo.

* ABSTRACT: The objective of this paper is to present and discuss some data and information about the diffusion process of microeletronic technology in the continuous process industry in Brazil. The data presented show the high level of diffusion of this technology in relation to the discrete parts manufacturing industry. The base installed in Brazil is proportionally larger than those of industrialized countries. The decision to adopt the microelectronic technology in this industry is strongly influenced by variables of "sócio-institutional" nature, as the technical and economic information are not always promptly available. Among the "socio-institutional" variables analysed, the impact of the market reserve policy on the diffusion process is given special attention.

* KEY WORDS: Microeletronic, difusion, continuous process industries.

São Paulo, 32(5):16-26 


\section{INTRODUÇÃO}

No atual contexto de implementação de políticas econômicas com o objetivo explícito de promover o aumento da produtividade e, portanto, a competitividade do parque industrial brasileiro, tornase de fundamental importância aprofundar o conhecimento a respeito dos fatores que influenciam a sua dinâmica competitiva. É hoje amplamente reconhecido o fato de que o rápido processo de difusão das tecnologias de base microeletrônica tem provocado profundas mudanças na esfera da produção, afetando significativamente a competitividade das empresas. No entanto, ainda é generalizada a carência de conhecimentos sobre o processo de difusão tecnológica, principalmente no contexto de países que possuem características peculiares quanto ao seu processo de industrialização.

Por certo, a falta de maior amplitude conceitual e empírica sobre as características do processo de difusão tecnológica contribui para as divergências de interpretação observadas. Os estudos mais recentes sobre difusão identificam sérias lacunas na teoria tradicional, que procurava explicar os padrões de difusão apenas em termos de decisões racionais dos agentes envolvidos no processo. De acordo com esta visão, as variáveis-chave para explicar o processo de adoção de novas tecnologias diziam respeito à taxa de lucro esperado, escala de investimentos necessários e possíveis dificuldades técnicas ${ }^{1}$.

Mais recentemente, alguns estudos chamaram atenção para a influência do ambiente sócio-econômico no processo de difusão de novas tecnologias. Mudanças nas condições sócio-econômicas durante o processo de difusão podem atuar no sentido de redirecionar o seu padrão, indicar novas oportunidades de inovação e, dessa forma, modificar as características iniciais de um dado paradigma tecnológico. Entre as variáveis que compõem as condições sócio-econômicas, Freeman e Perez ${ }^{2}$ destacam aquelas de origem social e institucional que, segundo eles, são específicas a cada contexto.

Partindo-se desta premissa, alguns aspectos gerais, relacionados às condições encontradas no Brasil para a difusão da microeletrônica, podem ser apontados.
Em primeiro lugar, reconhece-se que as normas de produção fordistas - forma prevalecente de organização da produção e consumo na etapa anterior à difusão da microeletrônica - não se encontram totalmente disseminadas no país. Essa constatação tem sérias implicações na utilização dos novos sistemas produtivos, uma vez que a norma fordista pressuponha certos

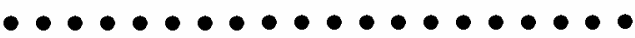

\section{Trata-se de substituir uma cultura de organização tradicional (fordista) por uma cultura que requer novas visões estratégicas, novos graus de integração novas qualificações profissionais.}

padrões de relações de trabalho, incluindo distribuição salarial e de renda ${ }^{3}$.

Segundo, é importante ressaltar que a introdução e difusão do paradigma microeletrônico no país têm por base a importação de grande parte do conhecimento necessário, seja ele embutido em equipamentos, ou sob a forma da transferência de informações técnicas e científicas.

Esse aspecto é importante não só do ponto de vista da sua influência sobre a velocidade do processo de difusão, mas, também, pelo seu impacto na mudança da cultura da organização e seu posicionamento estratégico. Trata-se de substituir uma cultura de organização tradicional (fordista) por uma outra cultura que requer novas visões estratégicas, novos graus de integração entre as diferentes esferas da empresa e novas qualificações profissionais. A introdução da tecnologia de base microeletrônica ao nível da empresa é influenciada, de acordo com estudos empíricos ${ }^{4}$, pela atitude $e$ objetivos gerenciais ao adotar o novo sistema técnico: quanto mais claro o objetivo estratégico da mudança tecnológica, maior seria o seu impacto na competitividade da empresa.

Em terceiro lugar, deve-se levar em conta que o processo de difusão da microeletrônica no Brasil é fortemente influenciado pelas políticas governamentais para o setor, que, até então, têm sido con-
1. MANSFIELD, E. "Technical change and the rate of imitation". Econometrica, Nova lorque, 29(4):741-66, 1961.

2. FREEMAN, C. \& PEREZ, C. The diffusion of technical innovations and changes of technoeconomic paradigm. Brighton, Science Policy Research Unity, University of Sussex (mimeo), 1985

3. BOYER, R. Teoria da Regulaçāo: uma análise crítica, São Paulo, Nobel, 1990.

4. BODY, D. "Information Technology and Organizations: some recent findings". In: B.C. SMITH e D.C. PITT (eds.) The computer revolution in Public Administration, Sussex, Harvest Press, 1985. 
5. WOODWARD, J. Organização industrial: teoria e prática. São Paulo, Atlas, 1977; KATZ, J. "Comparative advantagens of Latin American metalworking industries". In: K. KING e M. FRANSMAN (eds.) Tecnological Capabilities in the Third World. London and Basingstoke: the Macmillan Press, 1984. substanciadas na lei de reserva de mercado. Essa política, além de influenciar a taxa e velocidade de difusão, implica na adoção de certas normas técnicas que são relacionadas aos padrões produtivos dos supridores nacionais de equipamentos microeletrônicos, o que, certamente, vem direcionando a forma de utilização desses equipamentos.

Por último, estudos anteriores ${ }^{5}$ levantaram a hipótese que a continuidade dos processos produtivos afeta o tipo de organização interna da empresa e seus sistemas de controle (estoques, qualidade etc). Dessa forma, a implementação de tecnologias de base microeletrônica poderá ter efeitos diferenciados na organização, de acordo com o nível de continuidade do processo de produção dos usuários, o que afetaria o processo de difusão.

Nesse sentido, muitos estudiosos afirmam que os sistemas de controle de processos digitais são importantes instrumentos para aumentar a flexibilidade, qualidade e produtividade na indústria de processo contínuo. Afirma-se, também, que a mudança nos sistemas de controle de processo gera importantes modificações nas práticas gerenciais e na organização da produção e do trabalho, demandando novas qualificações, tanto por parte dos gerentes como dos trabaIhadores. Evidentemente, estas afirmações não são aceitas por todos aqueles envolvidos com o estudo e na prática dessa área de automação de processo contínuo. Mesmo que haja mudanças, argumentase, elas são evolucionárias e não revolucionárias. Além disso, mudam-se apenas os instrumentos de controle, não o processo em si. Seria uma mudança bastante diferente da indústria seriada. Logo, não se poderia falar em mudanças radicais decorrentes da automação digital na indústria de processo contínuo.

Controvérias à parte, o estudo da difusão de tecnologia de base microeletrônica na indústria de processo contínuo justifica-se pelos seguintes argumentos:

a. a importância econômica dessa indústria em qualquer parque industrial. São setores de processo contínuo: a refinação de petróleo, química/petroquímica, siderurgia, papel e celulose, mineração e cimento, vidro, entre ou- tros ramos industriais;

b. vários desses setores (refinação de petróleo, química/petroquímica, papel e celulose, mineração) estão em processo de ampliação bastante significativo, e seus novos sistemas de controle serão, inevitavelmente, digitalizados;

c. o nível mais avançado de difusão da tecnologia digital, quando comparado com a indústria de processo intermitente;

d. por último, o tamanho do parque produtor de equipamentos de automação digital de processo instalado no país.

Tomando como ponto de partida as observações acima levantadas, pretendese, neste trabalho, apresentar e discutir dados e informações a respeito do processo de difusão da tecnologia digital na indústria de processo contínuo no Brasil. Para tanto, são apresentados os dados que indicam o nível de aprofundamento da difusão. Em seguida, são analisados os fatores identificados como inibidores $\mathrm{e}$ aceleradores desse processo. Apresentase, também, um panorama da indústria produtora de equipamentos digitais para controle de processo. Por fim, são discutidos os resultados à luz dos elementos conceituais levantados nessa introdução.

\section{DIFUSÃO}

\section{A tecnologia}

Os novos equipamentos de base digital para indústrias de processo contínuo atuam, em um primeiro nível mais fundamental, na área de controle de processo. Os equipamentos de controle de processo - digitais ou analógicos convencionais - permitem que a transformação de matéria-prima em produto final seja controlada à distância, eliminando as relações do homem com o produto nas suas diversas fases de transformação.

Em indústrias de processo semicontínuo (como a siderurgia), os equipamentos digitais permitem, além do controle localizado dos processos, a integração das diversas "fábricas" (por exemplo: redução, aciária, laminação etc.), possibili- 
tando a diminuição dos pontos de descontinuidade do fluxo produtivo ${ }^{6}$.

Nos processos contínuos, o trabalho humano fica restrito às tarefas de monitoração e controle dos equipamentos, através da observação de um conjunto de variáveis: temperatura, pressão, níveis, fluxos, vazões, tensão, corrente, potência, velocidade, rotação etc. Em essência, o trabalho consiste em manter essas variáveis o mais próximo possível de certos parâmetros. A atividade produtiva nesse caso já é bastante automatizada, uma vez que se espera que não exista interrupção no processo (salvo para manutenção periódica, paradas etc.), nem inter-relação direta do trabalho humano com o produto ou o sistema de transformação. A importância do trabalho humano evidenciase quando ocorrem anormalidades ou emergências.

Os sistemas de controle baseados em microeletrônica representam o estágio tecnológico mais avançado. Antes, os sistemas analógicos predominavam, com suas vertentes pneumática e eletrônica.

Os principais equipamentos digitais para controle de processo são os seguintes:

\section{- Controlador Lógico Programável - CLP}

Equipamento que executa instruções de controle de máquinas e operações de processo. É constituído de CPU, memória e módulos de entrada e saída com interfaces variadas, de acordo com a aplicação.

- Controladores single-loop e multiloop

São controladores que possuem uma configuração de hardware mais simples que o CLP. São utilizados no processamento de "malhas" de variáveis analógicas.

\section{- Computador de Processo}

Sistema de supervisão e controle de processos dedicados, fabricados especialmente para operar em alta e baixa temperatura e oferecer maior resistência a impactos.

- Sistema Digital de Controle Distribuído-SDCD

O SDCD é um conjunto de estações de controle baseadas em microprocessadores que se interligam e são reunidos em uma estação de trabalho de 32 bits, constituída de teclados, vídeos e terminais de saídas.

Além de realizar as atividades de controle de processo propriamente ditas, os equipamentos de base microeletrônica ainda permitem a integração entre o controle digital de processo, computadores de processo com software de modelagem e simulação, e computadores que operam sistemas de apoio gerencial. As técnicas de modelagem e simulação substituem, em grande parte, as plantas-piloto nos trabalhos de acompanhamento e desenvolvimento de processos, que têm como finalidade modificar e otimizar as condições de operação. Para isso, torna-se necessário desenvolver modelos matemáticos das reações e operações unitárias envolvidas e traduzi-los em software. Com os sistemas digitais de controle de processo fica mais fácil e rápida a alimentação de computadores aptos a, partindo de modelos matemáticos, simular as reações e demais operações envolvidas com dados reais e em tempo real. Por sua vez, a integração com o computador de apoio gerencial permite que sistemas administrativos (custos, estoques, finanças etc.) e de coordenação (sistemas de informações gerenciais) sejam alimentados diretamente com os dados reais de produção selecionados.

A integração dos sistemas digitais de controle de processo com computadores de processo e gerenciais significa uma etapa mais avançada na utilização de nova tecnologia. Ela permite que uma planta de processo contínuo seja operada com parâmetros mais adequados de estabilidade e flexibilidade, condições essas que impactam positivamente na qualidade do produto e na rentabilidade geral da empresa. No entanto, esse tipo de integração exige um nível mais elevado de capacitação tecnológica do usuário, que transcende a simples implantação de controles digitais. Em geral, para se obter a integração entre os diversos sistemas, necessita-se de um trabalho de desenvolvimento próprio, uma vez que não existem soluções prontas disponíveis no mercado. $\mathrm{Na}$ indústria de processo contínuo, a utilização dos equipamentos digitais vi-
6. FERREIRA, C. "Sistemas de controle de processo na siderurgia: aspectos ligados ao impacto na mão-de-obra". Anais do Seminário Nacional Difusão e Impactos da Automação na Indústria. Salvador, ISP/UFBA 1989. 


\section{TABELA 1}

\section{Mercado Mundial de Automação Industrial (em US\$ milhões)}

\begin{tabular}{lrrrr}
\hline Equipamentos & $\mathbf{1 9 8 5}$ & $\%$ & $\mathbf{1 9 9 0}$ & $\%$ \\
\hline Controladores de Processo tipo CLP & 904 & 8 & 2.334 & 6 \\
\hline Máquinas-Ferramenta CN & 1.469 & 13 & 1.945 & 5 \\
\hline Robôs & 565 & 5 & 2.334 & 6 \\
\hline Outros CPs & 2.373 & 21 & 10.892 & 28 \\
\hline Equipamentos de transporte de material & 1.017 & 9 & 1.945 & 5 \\
\hline Equipamento de teste & 1.356 & 12 & 3.890 & 10 \\
\hline Software para sistemas Al & 226 & 2 & 778 & 2 \\
\hline Plantas automatizadas(CIM e SFM) & 3.376 & 30 & 14.782 & 38 \\
\hline ToTAL & $\mathbf{1 1 . 3 0 0}$ & $\mathbf{1 0 0}$ & $\mathbf{3 8 . 9 0 0}$ & $\mathbf{1 0 0}$ \\
\hline
\end{tabular}

Fonte: INTERNATIONAL DATA CORPORATION. "Mercado Mundial de Automação Industrial". The Economist, maio 1987.

7. CHEMICAL WEEK. COMOUters in the CPI: tying it all together. Londres, Outubro, 1990. pp. $22-35$. sando à integração corresponde, portanto, a um posicionamento estratégico de uma empresa em relação a essa tecnologia, que se diferencia do posicionamento tático, limitado ao uso de instrumentação digital de controle de processo em lugar da instrumentação analógica convencional.

\section{Nivel de difusão}

A tabela 1 apresenta dados sobre o mercado mundial de automação industrial, segmentado por tipos de equipamentos. A participação dos equipamentos utilizados na indústria de processo contínuo (Controladores de Processo tipo CLP e outros CPs) representava $29 \%$ do mercado total em 1985, prevendo-se que tenha crescido para $34 \%$ em 1990. Esses dados indicam um alto grau de difusão, considerando a participação dos setores de processo contínuo no produto industrial, setores estes com alta concentração de capital e muito propensos a economias de escala.

Os dados para os EUA apresentados pela Chemical Week ${ }^{7}$ indicam que os investimentos da indústria química de processo em equipamentos digitais, em 1989, foram da ordem de US\$ $910 \mathrm{mi}-$ Ihōes em equipamentos de controle $\mathrm{e}$ US\$ 361,5 milhöes em computadores de que, ao redor do mundo, as empresas químicas estāo investindo cerca de $4 \%$ processo. A mesma publicação estima das vendas em equipamentos digitais, incluindo desde sistemas de informaçōes gerenciais, passando por equipamentos de controle e de otimização de processos, até sistemas de gerência de informaçōes laboratoriais.

As pressōes ambientalistas têm contribuído para aumentar os investimentos em sistemas digitais. Segundo a mesma Chemical Week, nos EUA, o Clean Air Act além de novas regulamentaçōes na área de segurança, saúde ocupacional e emissão de efluentes - vem levando as empresas a atribuirem um valor estratégico às informaçōes de controle de processo, ao invés de considerá-las um mero item tecnológico. Os sistemas digitais permitem um maior controle das variáveis críticas na operaçāo dos processos.

A tabela 2 apresenta os dados do mercado de automação industrial no Brasil, segmentado por tipos de equipamentos. Note-se que os equipamentos para indústria de processo contínuo (SDCD, CLP, outros CPs) representavam, em 1988, $50,2 \%$ do mercado total. Essa participação é bem maior que os $34 \%$ do mercado internacional em 1990. De fato, dados da

\section{TABELA 2}

\section{Mercado brasileiro de equipamentos de automação: faturamento dos principais segmentos (1988) (em US\$1000)}

\begin{tabular}{lrr}
\hline SEGMENTOS & FATURAMENTO & $\%$ \\
\hline SDCD & 35.000 & 9,2 \\
\hline CP & 50.000 & 13,0 \\
\hline CN/CNC & 27.000 & 7,0 \\
\hline CAD/CAM & 36.000 & 9,5 \\
\hline ROBÓTICA & 2.000 & 0,5 \\
\hline TESTES & 34.000 & 9,0 \\
\hline ENGENHARIA & 90.000 & 23,8 \\
\hline OUTROS CPS (1) & 105.000 & 28,0 \\
\hline
\end{tabular}

Fonte: BNDES. Microeletrônica e Informática: uma abordagem sob o enfoque do complexo eletrônico. Rio de Janeiro, Área de Planejamento, Departamento de Estudos, BNDES, 1990.

(1) Controladores de Demanda (CD), Single-loop (SL), Multi-loop (ML), Sistemas de Controle de Aquisiçāo de Dados (SCADA) e Computadores de Processo (CPR). 
$\mathrm{SEI}^{8}$ indicam que, em $1987,60,9 \%$ do valor da base instalada de automação industrial correspondiam a equipamentos de controle de processos. Do total desses equipamentos, os Controladores Lógicos Programáveis representavam quase $60 \%$ sobre 0 valor do parque instalado nessa área, embora venham perdendo terreno em participação desde 1984. Os SDCDs são os que mais cresceram no período, atingindo, em $1987,35 \%$ do valor do parque instalado na área de controle de processo.

Em termos quantitativos, a SEI indica ainda que, de 84 a 87 , o número de equipamentos de controle de processos cresceu mais, percentualmente, do que o número de equipamentos de automação da manufatura. O SDCD, no entanto, somente em 1985, começa a ser instalado no
Brasil, chegando, em 1987, a atingir uma base de 64 unidades. Neste mesmo ano, havia 11.905 Controladores Lógicos Programáveis e 1.691 Controladores de Processo single-loop e multi-loop instalados.

Em 1988, foi feita uma projeção da demanda por equipamentos e serviços de automação discriminada por setores usuários. Os resultados são apresentados na tabela 3. Entre os setores que apresentaram maior crescimento em valores estão o metal-mecânico, petróleo e petroquímico, siderúrgico, químico e produtos derivados, e papel e celulose. Fora o setor metal-mecânico, todos os outros são consumidores de equipamentos de controle de processo. Em termos percentuais, o setor siderúrgico é o que apresenta maior potencial de crescimento, certamente de-

\section{TABELA 3}

\section{Projeção de demanda, por setor usuário, de equipamentos e serviços de automação industrial (em US\$1000)}

\begin{tabular}{lrrrr}
\hline SETORES & $\mathbf{1 9 8 9}$ & $\mathbf{1 9 9 0}$ & $\mathbf{1 9 9 1}$ & $\mathbf{1 9 9 2}$ \\
\hline Agroindústria & 36.240 & 53.500 & 83.090 & 105.460 \\
\hline Cimento, Ceråmica,Vidro & 12.130 & 14.780 & 19.500 & 24.800 \\
\hline Eletroeletrônico & 50.500 & 58.160 & 75.360 & 92.200 \\
\hline Geração/Distrib. Energia Elétrica & 15.080 & 22.570 & 35.200 & 45.060 \\
\hline Metal-Mecânico & 153.150 & 195.790 & 263.020 & 445.530 \\
\hline Papel e celulose & 28.680 & 40.790 & 53.300 & 65.970 \\
\hline Petróleo e Petroquímica & 129.770 & 184.770 & 283.850 & 352.000 \\
\hline Plástico/borracha & 16.530 & 19.160 & 25.520 & 44.620 \\
\hline Química e produtos derivados & 36.940 & 44.760 & 59.060 & 74.790 \\
\hline Siderurgia & 20.120 & 43.330 & 67.720 & 86.980 \\
\hline Têxtil e Vestuário & 11.230 & 13.840 & 18.070 & 22.470 \\
\hline Transporte & 9.000 & 13.680 & 19.530 & 27.570 \\
\hline Mineração & 7.910 & 9.450 & 12.390 & 15.540 \\
\hline Metalurgia & 10.920 & 15.140 & 20.130 & 25.830 \\
\hline Não Ferrosos & 7.640 & 13.740 & 19.720 & 24.640 \\
\hline Serviços Públicos & 10.440 & 17.140 & 27.050 & 35.390 \\
\hline Construção & 10.740 & 14.130 & 18.480 & 23.020 \\
\hline Editorial/gráfica & 3.520 & 4.250 & 5.570 & 6.950 \\
\hline Armazenagem & 2.050 & 2.780 & 3.730 & 4.830 \\
\hline Total & $\mathbf{5 7 2 . 5 9 0}$ & $\mathbf{7 8 1 . 7 6 0}$ & $\mathbf{1 . 1 1 0 . 2 9 0}$ & $\mathbf{1 . 5 2 3 . 6 5 0}$ \\
\hline
\end{tabular}

Fonte: INTERBUSINESS CONSUL TORIA EMPRESARIAL."Estudo setorial do mercado brasileiro de automaçāo industrial", 1992. Gazeta Mercantil. 28 e 30/01/1989, p. 11.
8. SEI, Parque de equipamentos de informática. Série EstatistiCas, SEl, Brasília, 1988. 
9. CARVALHO, R. Q.; RABELO, F. M; ALMEIDA, L.T.; COSTA, M.C. Microeletrônica, capacitação tecnológica, competitividade e trabalho na indústria petroquímica brasileira. Campinas, UNICAMP/DPCT (mimeo), 1988

10.BNDES. Microeletrônica $e$ lnformática: uma abordagem sob o enfoque do complexo eletrônico. Rio de Janeiro, Área de Planejamento, Departamento de Estudos, BNDES, 1990.

11. CRIVELLARI, H. \& TEIXEI$R A, F$. "Impactos da tecnologia de base microeletrônica na indústria de processo contínuo: um estudo de caso na petroquimica". Revista de Administração Pública, 24(1):122-42, 1990.

12. CRIVELLARI, H. \& TEIXEIRA, F. Idem, ibidem

13. CRIVELLARI, H. \& TEIXEIRA, F. Idem, ibidem. vido à sua defasagem na área de automação. No entanto, as incertezas que rondam os investimentos das usinas estatais, já em processo de privatização, poderão retardar sua atualização tecnológica. Já os setores de petróleo, petroquímica, e papel e celulose deverão representar o principal mercado para automação, uma vez que já se encontram em processo de ampliação significativa de capacidade. $\mathrm{O}$ Plano Nacional de Papel e Celulose, por exemplo, prevê investimentos totais de US\$ 7 bilhões até 1995, dos quais US\$ 1 bilhão serão gastos com instrumentação. Destes, $93 \%$ serão gastos em equipamentos digitais.

Em termos de tipos de equipamentos, essas mesmas projeções também indicam um acentuado crescimento da demanda em controle de processos. Os Controladores Lógicos Programáveis deverão crescer $187 \%$ no período $88 / 92$, e os SDCDs $114 \%$ no mesmo período. Esses números só são superados pelos Controladores Núméricos Computadorizados (utilizados em máquinas-ferramenta) que crescerão 359\% até 92.

Já em 1986, uma pesquisa realizada pela ABIQUIM (Associação Brasileira da Indústria Química) detectava um bom nível de difusão do controle digital na indústria química/petroquímica. Da amostra de 51 empresas, 39\% usavam algum tipo de equipamento de controle digital, das quais 21,5\% (11 empresas) possuiam SDCD, muito embora apenas duas plantas fossem inteiramente controladas por SDCD. Esses números indicam que o padrão de difusão desses equipamentos está sendo seletivo: em geral, as empresas preferem introduzir a tecnologia paulatinamente em substituição à instrumentação convencional, adotando o controle digital mais amplo (SDCSs) quando da expansão de capacidade ou construção de novas plantas.

A partir dos dados disponíveis, podese afirmar que o processo de difusão da microeletrônica na indústria de processo contínuo é mais abrangente do que na indústria de produção intermitente ou seriada (manufatura), e que essa tendência deverá se manter nos próximos anos. Algumas explicações para esse fenômeno podem ser apontadas. Em primeiro lugar, a maioria dos setores que operam processos contínuos (petroquímica, e papel e celulose, por exemplo) são setores modernos, recentemente implantados e que passam por um processo de significativa expansão de capacidade. Por outro lado, são setores que criaram uma ca-

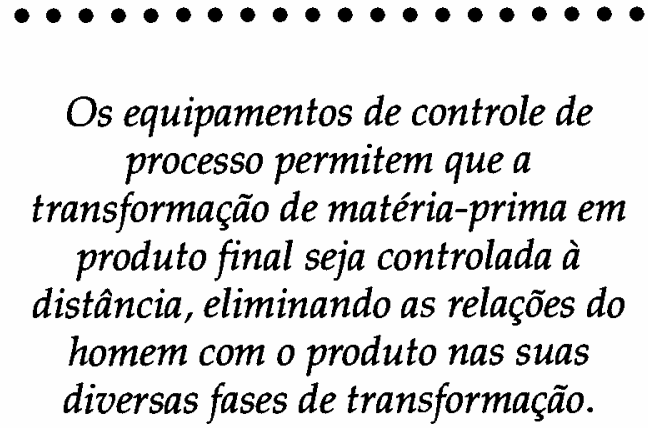

pacitação tecnológica considerável, que os tornou aptos a conviver com a nova tecnologia?.

Além disso, por serem, em geral, setores que participam do mercado externo, as exigências quanto à produtividade $\mathrm{e}$ qualidade tornariam a atualização tecnológica imperativa ${ }^{10}$. Por fim, o uso da tecnologia microeletrônica em processos contínuos não provoca alterações tão radicais no processo de trabalho como aquelas reportadas para o caso dos processos intermitentes ${ }^{11}$. Essa característica facilitaria a introdução dos novos equipamentos do ponto de vista das relações de trabalho e da organização do sistema sócio-técnico.

No entanto, do ponto de vista de um posicionamento estratégico em relação à tecnologia, alguns desses argumentos podem ser mudados. Por um lado, a integração sistêmica da empresa requer um nivel de capacitação tecnológica que não se encontra disseminado na indústria brasileira, apesar dos exemplos isolados ${ }^{12}$. Por outro lado, a obtenção de padrões elevados de produtividade e acompanhamento de sua dinâmica a nível internacional depende da integração sistêmica. Por último, a integração sistêmica pressupõe mudanças fundamentais na filosofia e na "cultura" organizacional ${ }^{13}$, que implicam problemas tão ou mais intensos que as mudanças nas relações e organização do trabalho.

De qualquer forma, o aprofundamento 
do processo de difusão da tecnologia digital na indústria de processo contínuo dependerá, em parte, da disponibilidade dos equipamentos no mercado. Como até então essa área esteve protegida pela reserva de mercado, uma breve análise da indústria produtora de equipamentos no Brasil será esboçada no próximo item.

\section{A INDÚSTRIA PRODUTORA DE EQUIPAMENTOS}

De acordo com Tigre ${ }^{14}$, a indústria produtora de equipamentos de automação industrial no Brasil é caracterizada, por um lado, pelo fato de a maioria dos fabricantes ser de pequeno porte ( $83 \%$ das empresas têm menos de 500 empregados). Por outro lado, essa indústria apresenta um elevado grau de concentração. Algumas empresas são orginárias de grupos industriais previamente instalados, ou são vinculadas a grupos econômicos diversificados. As quatro maiores empresas apresentadas na tabela 4 estão nessa categoria. A tabela 4 informa também que, das dez maiores empresas, seis são fabricantes de equipamentos de automação de processos contínuos (SDCD e CLP).

Segundo, a revista Automação e Indústria ${ }^{15}$, existem no Brasil 18 fabricantes de SDCD, 18 de CLP e 12 de CDP. Dos fabricantes de SDCD, 5 sāo signatários de acordos de transferência de tecnologia com empresas estrangeiras. Esses fabricantes atendem o mercado mais sofisticado, principalmente aqueles usuários que operam processos de maior porte. Os outros fabricantes utilizam tecnologia desenvolvida no país, aproveitando os incentivos da política de reserva de mercado. A maioria dos fabricantes possui linhas de produlos diversificadas.

Em 1984, a SEI autorizou cinco empresas nacionais a transferirem tecnologia para desenvolver SDCDs e estipulou que até o final de 1987 os fabricantes atingissem um coeficiente de nacionalização de 85\%. A Ecil P\&D associou-se à japonesa Yokogawa; a Elebra, à Leeds \& Northrup; e a Unicontrol, à Fischercontrol. A Villares associou-se à Hitachi e a DFV, à sueca Asea. Em 1988, a mesma SEI autorizou mais dois contratos: a Villares com a Honeywell e a DFV com a mesma Asea. A justificativa era que a oferta de equipa-

\section{TABELA 4}

\section{Faturamento das dez maiores empresas brasileiras de automação industrial (1988) (em Cz\$ milhões)}

\begin{tabular}{lrr}
\hline EMPRESA & FATURAMENTO & PRODUTOS \\
\hline Villares Informática & 6.712 & CAD, SA \\
\hline Romi & 4.824 & MFCN \\
\hline Comsip & 4.608 & SDCD \\
\hline Metal Leve Controles & 3.845 & CLP, CN \\
\hline Maxitec & 3.758 & CN, CLP \\
\hline Ecil/P\&D & 2.868 & SDCD \\
\hline Digicon & 2.676 & Plotters, CN, CLP \\
\hline CMW & 2.433 & SDCD \\
\hline Comicro & 1.659 & CAD/CAM \\
\hline Sisgraph & 1.499 & CAD \\
\hline
\end{tabular}

Fonte: TIGRE, F. "Indústria de equipamentos de automação industrial: implicaçốes para competitividade brasileira". In: Anais do Seminário Nacional Difusão e Impactos da Automação Digital na Indústria. Salvador, ISP/UFBA, 1989.

mentos voltados para a área de petróleo e petroquimica seria insuficiente para atender à demanda.

$\mathrm{Na}$ visão de Tigre ${ }^{26}$, os preços dos equipamentos brasileiros de automação industrial não são competitivos em relação aos praticados no mercado internacional. No entanto, no caso dos equipamentos para processos contínuos (principalmente os mais sofisticados), a necessidade do desenvolvimento de soluções específicas para cada usuário (além da assistência técnica e treinamento) constitui uma importante barreira à entrada de produtos importados. De fato, a utilização de um SDCD é precedida de todo um trabalho de configuração do sistema. Esse trabalho deve ser realizado pela equipe do fabricante em conjunto com o usuário. Admite-se que, nessa tarefa, o conhecimento a respeito do processo que vai ser objeto de controle é tão importante quanto o conhecimento do sistema ou mais importante do que o conhecimento do sistema ou do software de configuração. Portanto, da natureza da integração do fabricante com o usuário vai depender, em grande parte, o bom aproveitamento do equipamento a ser instalado.

Os aspectos de manutenção e treinamento também são críticos. A confiabili-
14. TIGRE, F. "Indústria de equjpamentos de automação industrial: implicações para competitividade brasileira". In: Anais do Seminário Nacional Difusão e Impactos da Automação Digital na Indústria. Salvador, ISP/UFBA, 1989.

15. AUTOMAÇÃO E INDÚSTRIA, Rio de Janeiro, Ano II!, julho 1989.

16. TIGRE, P. Op. cit 
17. GERHARD, M. "Resultados econômicos obtidos com a automação de processos". In: 7 Seminário de Instrumentação, Rio de Janeiro, IBP, 1987.

18. BOCHINI, L. "Implantação de SDCD, em planta integrada de oxo-álcoois e isoparafinas". Anais do III Seminário de Instrumentação, Rio de Janeiro, IBP, 1985. dade do controle do processo depende, em grande medida, da eficiência na manutenção. $O$ sistema parado pode significar, além de perdas financeiras, riscos para todas as instalações, ao contrário da automação em processos seriados. Por sua vez, a carência de engenheiros e operadores já treinados no uso da nova tecnologia requer do fornecedor nacional uma boa capacidade de treinamento.

A integração dos sistemas

digitais de controle de processo

com computadores de processo e

gerenciais significa uma etapa mais

avançada na utilização de nova tecnologia.

\section{DETERMINANTES DA DIFUSÃO}

A análise dos determinantes do processo de difusão será feita agrupando-se três tipos de fatores: técnicos, econômicos e institucionais.

\section{Aspectos técnicos}

De acordo com a literatura, as vantagens técnicas do controle de processo digitalizado sobre o analógico são evidentes. Comparando o SDCD com a instrumentação convencional, por exemplo, Gerhard ${ }^{17}$ apresenta as seguintes vantagens:

- aumento da disponibilidade da planta,

- maior regularidade da produção,

- aumento dos rendimentos operacionais,

- maior facilidade na comunicação homem-processo,

- maior flexibilidade na operação e produção da planta,

- aumento da segurança das instalações,

- menor desgaste dos equipamentos,

- aumento da segurança do pessoal,

- maior conhecimento do processo,

- valorização do pessoal,

- maior integração da operação da planta com as atividades gerenciais e de planejamento e controle.
É importante observar que o real aproveitamento das vantagens técnicas do SDCD depende de algumas condições. Em primeiro lugar, depende da boa configuração do sistema - que depende, como já mencionado, do conhecimento prévio a respeito do equipamento digital e do domínio sobre técnicas de configuração - e, principalmente, do conhecimento sobre o processo de produção a ser controlado. Portanto, no caso de equipamentos importados, as condições da compra da tecnologia de processo podem afetar as vantagens técnicas do sistema digital, uma vez que o vendedor poderia encontrar dificuldades para ter pleno acesso às informações sobre o processo.

Em segundo lugar, depende da eficiente utilização do equipamento digital. Caso não haja treinamento adequado, o SDCD pode não apresentar as vantagens aduzidas. Na verdade, existem relatos informais de casos na indústria química brasileira em que a má operação de plantas é atribuída à má escolha e utilização do equipamento digital de controle de processo.

Por último, a obtenção das vantagens identificadas como "maior integração da operação" dependerá de dois fatores. $\mathrm{O}$ primeiro refere-se à atitude da empresa usuária frente à nova tecnologia: se a tecnologia for adotada com uma visão tática (em oposição à visão estratégica), as vantagens advindas da interação (já mencionadas) com outros sistemas informacionais não serão obtidas. Segundo, para obter as vantagens da interação, a empresa usuária precisa ter, ou desenvolver, uma capacitação tecnológica adequada tanto em tecnologia de processo, como em controle de processo e automação. Pode precisar, ainda, de uma nova concepção de organização do trabalho no interior das plantas.

\section{Aspectos econômicos}

Bochini ${ }^{18}$ apresenta uma comparação econômica entre a tecnologia digital e a convencional, reproduzida na tabela 5 .

Essa análise é claramente favorável ao SDCD, que teria um custo total próximo da metade do Sistema Analógico Convencional (SAC). No entanto, alguns as- 
pectos devem ser considerados. Primeiro, os valores estão calculados com base nos preços dos equipamentos no mercado externo. Os preços nacionais são reconhecidamente maiores. Segundo, deve-se atentar também para as dificuldades enfrentadas na realização de análises quantitativas de custo-benefício quando se planeja substituir uma instrumentação analógica pela convencional ${ }^{19}$. As decisões, na maioria das vezes, não são tomadas com base em vantagens "tangiveis e quantificáveis", conforme o jargão da área. Terceiro, em pelo menos uma empresa, construiu-se uma planta nova dotada da instrumentação convencional e da digital, trabalhando em paralelo. A justificativa era que, sendo uma tecnologia nova, o SDCD não ofereceria a devida confiabilidade, uma vez que o pessoal técnico operacional não estava familiarizado com ele. Por último, deve-se levar em conta o tamanho do sistema a ser controlado: quanto maior ele for, maior a vantagem econômica do SDCD.

Essas considerações sugerem que, pelo menos no atual estágio de difusão, o investimento em tecnologia digital seja encarado, em muitos casos, como um custo de aprendizado, dado que o futuro do controle de processo é, inevitavelmente, digital.

\section{Aspectos institucionais}

Como já assinalado por Crivellari e Teixeira ${ }^{20}$, a decisão da SEI de nacionalizar a produção da instrumentação digital foi um fator preponderante para reduzir o tempo de vida útil da instrumentação analógica já instalada. Avaliou-se em 1987 que, no prazo de 10 anos, já não haveria mais sobressalentes no país para esses equipamentos. A importação de sobressalentes não é uma alternativa que atraía a atenção pessoal da indústria. Portanto, independentemente de vantagens técnicas e econômicas, a política de automação industrial adotada tornou-se o estímulo mais importante à difusão de equipamentos digitais, quando se trata de substituir a instrumentação analógica em plantas já instaladas.

Some-se a esse aspecto o desenvolvimento de uma "cultura de informatização e automação" entre a nova geração de en-

\section{TABELA 5}

\section{Vantagens econômicas do SDCD (Custo em US\$1000)}

\begin{tabular}{|c|c|c|}
\hline DESCRIÇÃO & SDCD & $\overline{S A C}$ \\
\hline Instrumentação sala controle & 1.600 (CIF) & 2.300 \\
\hline Painel de controle & - & $260(200 \mathrm{~m})$ \\
\hline Sala de controle & $30(50 \mathrm{~m})$ & 120 \\
\hline Instalação & $50(50 \mathrm{~m})$ & 300 \\
\hline$\overline{\text { Total }}$ & 1.680 & 2.980 \\
\hline
\end{tabular}

Fonte: BOCHINI, L."Implantação de SDCD, em planta integrada de oxo-álcoois e isoparafinas". Anais do III Seminário de Instrumentação, Rio de Janeiro, IBP, 1985.

genheiros que trabalham nos setores de processo contínuo. Como a quantificação de vantagens econômicas é precária, a influência exercida pelo corpo técnico torna-se fundamental nas decisões. Afinal, a nova tecnologia, além de representar a imagem do futuro, confere prestígio e status aos engenheiros e à empresa.

\section{CONCLUSÕES}

A difusão da tecnologia de base microeletrônica na indústria de processo contínuo vem-se dando mais rapidamente do que na indústria de processo intermitente, tanto no Brasil como no exterior. Tudo indica que a principal razão dessa diferença diz respeito à própria natureza da tecnologia: por serem processos já controlados automaticamente (ainda que em base analógica), a introdução da nova tecnologia em processos contínuos acarreta poucas mudanças em termos de relações do trabalho, incluindo sua organização e cultura empresarial. Além disso, os controladores digitais não representam uma descontinuidade técnica significativa, uma vez que não interferem na natureza do processo de transformação. Eles enfrentam, portanto, menores obstáculos na sua adoção e efetiva utilização, quando comparados com a manufatura.

De acordo com os dados disponíveis, a base instalada de equipamentos digitais de controle de processo no Brasil é proporcionalmente maior do que nos países industrializados. Uma das hipóteses levantadas para explicar essa situação seria
19. ANDREONI, B. "Difusão da tecnologia de controle de processo no Brasil". In: Anais do Seminário Nacional Difusão $e$ Impactos da Automaçāo Digita! na Indústria. Salvador. ISP/UFBA, 1989.

20. CRIVELLARI, H. \& TEIXEIRA, F. Op. cit. 
a maior capacitação tecnológica relativa das indústrias de processo contínuo, quando comparada com a da maioria dos setores de produção intermitente, que, no país, apresenta um nível ainda incipiente de difusão de equipamentos digitais. De fato, o domínio da tecnologia digital e da tecnologia do processo de transformação é um fator preponderante tanto na decisão de usar a nova tecnologia, como no sucesso da sua utilização.

A capacitação tecnológica da empresa usuária é importante para definir também o nível de utilização da microeletrônica. Quanto maior a capacitação existen-

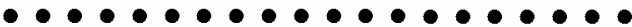

\section{Dentro do contexto da indústria brasileira que opera processos contínuos, a reserva de mercado contribuiu para acelerar o processo de difusão.}

$\bullet \bullet \bullet \bullet \bullet \bullet \bullet \bullet \bullet \bullet \bullet \bullet$

te, maior a possibilidade de a empresa auferir os ganhos potenciais de produtividade da nova tecnologia. Para isso, torna-se necessário adotar uma visão estratégica do uso da microeletrônica. Isso significa, no caso de processos contínuos, uma gradativa integração dos sistemas de controle de processo, otimização e desenvolvimento de processo e sistemas de apoio gerenciais. Essa integração pode implicar em mudanças organizacionais com um grau de complexidade e incerteza semelhantes ao das mudanças verificadas em processos de automação de sistemas intermitentes de produção. Em suma, a mudança tecnológica e a mudança no sistema sócio-técnico são variáveis que não podem ser tratadas isoladamente, caso o objetivo seja obter ganhos reais de produtividade a longo prazo.

As informações apresentadas neste trabalho parecem confirmar que a teoria tradicional de difusão não leva em conta todas as variáveis intervenientes no processo. Verificou-se que considerações de natureza econômica e técnica nem sempre respondem pela decisão dos agentes econômicos ao adotar a nova tecnologia. $\mathrm{Na}$ verdade, os benefícios econômicos e téc- nicos quase sempre são intangíveis e incomensuráveis em virtude, principalmente, das incertezas quanto do desenvolvimento e posterior eficiência das aplicações reais. Em outras palavras, as informações necessárias a uma substanciada análise custo-benefício simplesmente não estão disponíveis no momento da tomada de decisão.

Portanto, a decisão de adotar a tecnologia digital é fortemente influenciada, nesse caso, por variáveis de natureza "sócio-institucional". A Política Nacional de Informática, ao tornar incerta a importação de sobressalentes analógicos e ao incentivar a implantação de uma significativa indústria produtora de equipamentos, constituiu-se, mesmo que indiretamente, na principal incentivadora da adoção da microeletrônica, nos casos em que a decisão envolve a substituição da instrumentação analógica pela digital.

Por outro lado, o alto preço dos equipamentos digitais produzidos no país constitui um obstáculo à difusão da nova tecnologia. Porém, observa-se que a formação de uma incipiente "cultura" de informatização e automação no meio técnico da indústria de processo contínuo contribui para que as decisões quanto à adoção sejam tomadas, mesmo sem serem amparadas por análises técnicas e econômicas claras.

Cabe ainda reconhecer que a caracterização do contexto onde se dá o processo de difusão de uma nova tecnologia é essencial para identificar a sua velocidade e direção, bem como prever os impactos na competitividade dos usuários. Dentro do contexto da indústria brasileira que opera processos contínuos, a reserva de mercado contribuiu para acelerar o processo de difusão. Além de tornar disponíveis os equipamentos no país, criou uma infra-estrutura para desenvolver aplicações, realizar treinamento e proceder à manutenção dos sistemas de acordo com as necessidades dos usuários. Porém, dada a decisão política de abrir o mercado interno, indaga-se: qual será o impacto dessa decisão na indústria produtora de equipamentos? De que forma a velocidade da difusão será afetada? Qual a possibilidade de os setores usuários melhorarem o posicionamento competitivo? 